\title{
$\sqrt{12}$ \\ PR I F YS G OL \\ B A N G O R \\ UNIVERSIT Y \\ The complexities and challenges of conserving common whelk (Buccinum undatum, L.) fishery resources: Spatio-temporal study of variable population demographics within an environmental context.
}

Emmerson, Jack; Haig, Jodie; Bloor, Isobel; Kaiser, Michel

\section{Fisheries Research}

DOI:

10.1016/j.fishres.2018.02.015

Published: 01/08/2018

Peer reviewed version

Cyswllt i'r cyhoeddiad / Link to publication

Dyfyniad o'r fersiwn a gyhoeddwyd / Citation for published version (APA):

Emmerson, J., Haig, J., Bloor, I., \& Kaiser, M. (2018). The complexities and challenges of conserving common whelk (Buccinum undatum, L.) fishery resources: Spatio-temporal study of variable population demographics within an environmental context. Fisheries Research, 204, 125-136. https://doi.org/10.1016/j.fishres.2018.02.015

\footnotetext{
Hawliau Cyffredinol / General rights

Copyright and moral rights for the publications made accessible in the public portal are retained by the authors and/or other copyright owners and it is a condition of accessing publications that users recognise and abide by the legal requirements associated with these rights.

- Users may download and print one copy of any publication from the public portal for the purpose of private study or research.

- You may not further distribute the material or use it for any profit-making activity or commercial gain

- You may freely distribute the URL identifying the publication in the public portal ?
}

Take down policy

If you believe that this document breaches copyright please contact us providing details, and we will remove access to the work immediately and investigate your claim. 


\section{Journal:}

2 Fisheries Research

4 Title:

5 The complexities and challenges of conserving common whelk (Buccinum undatum L.) fishery

6 resources: spatio-temporal study of variable population demographics within an environmental context.

8 Authors:

9 Emmerson, J.A. ${ }^{1}$, Haig, J.A. ${ }^{1}$, Bloor, I.S.M. ${ }^{1}$ and Kaiser, M.J. ${ }^{1}$

10

11 Address:

$12{ }^{1}$ School of Ocean Sciences, College of Natural Sciences, Bangor University, Askew Street, Menai

13 Bridge, Anglesey, LL59 5AB, UK.

14

15 Email: j.emmerson@bangor.ac.uk

16 Keywords: commercial fishery, size at maturity, mollusc, gastropod, reproduction, fisheries,

17 management, gonadosomatic index.

\section{Highlights}

- Size-at-maturity (SOM) is estimated for a number of whelk populations in the Irish Sea.

- A rationale for a standard methodology for estimating SOM in B. undatum populations is presented.

- Environmental drivers of variable population demographics are investigated.

\section{Abstract}

The commercial fishery for common whelk (Buccinum undatum L.) has expanded significantly in the Irish Sea since 1990 and continues to grow, particularly in Welsh waters and the Isle of Man territorial sea, with landings throughout the region increasing by $227 \%$ between 2011 and 2016 . Whilst whelk populations are known to be vulnerable to localised overexploitation due to inherent life-history parameters, fisheries remain relatively unrestricted by conservation measures in comparison to other 
31 fisheries operating in the area. With the exception of the northernmost fishing ground between the Isle 32 of Man and Scotland (Point of Ayre), the size-at-maturity ( $\left.\mathrm{L}_{50}\right)$ estimate for populations sampled during 33 peak-aGSI (the months in which adjusted gonadosomatic index is highest) indicates that whelk are being 34 fished before the time at first spawning throughout the study area. A correlation was detected between 35 the size (total shell length) and depth, with smaller whelks found in deeper waters where there generally 36 is greater fishing effort, although effort data is not available at a resolution to investigate this relationship 37 quantitatively. No clear link between benthic infauna biomass and the average size (total shell length) or 38 reproductive capacity (aGSI) of whelk sampled throughout ICES Area VIIa was found, indicating that 39 the ecological energetics of whelk populations are more likely to be a function of scavenging 40 opportunities than predation on benthic communities. A mixed cohort analysis utilized length-based data 41 to infer a size-at-age relationship in the absence of direct age observations (e.g. statolith rings), with whelk recruiting into the Isle of Man fishery five years after hatching. The evidence presented in this study suggests that, prior to recommending a MLS that will adequately protect the spawning stock biomass, $\mathrm{L}_{50}$ values should be adjusted for pre-spawning growth between the ideal time of assessment (when aGSI values are at a peak) and the spawning season (when aGSI values decrease).

\subsection{Introduction}

The common whelk (Buccinum undatum, Linnaeus, 1758) is a neo-gastropod mollusc that is found in the subtidal waters of the North Atlantic to depths of $1200 \mathrm{~m}$ (Ager, 2008). It is widely distributed on the Atlantic continental shelf; from within the arctic circle $\left(76^{\circ} \mathrm{N}\right)$ as far south as New Jersey, USA at the western-most extent $\left(38^{\circ} \mathrm{N}\right)$ (Van Guelpen et al., 2005; Borsetti et al., 2018). Populations are most frequently observed in abundance in the northeast Atlantic, particularly in the waters of north-western Europe, from the Celtic and Irish Sea through to the Skagerrak and Kattegat Bay, including northern populations observed in Norwegian, Faroese and Icelandic waters (Ocean Biogeographic Information System, 2017).

Whelk are opportunistic scavengers that feed mainly on carrion (Nasution \& Roberts, 2004) and detect feeding opportunities with a very acute chemo-sensory system (Himmelman, 1988). This allows whelks to be commercially exploited by fishers, who typically use specifically designed baited traps. Inshore whelk populations have been exploited by a mixed artisanal fishery in Europe since the early $20^{\text {th }}$ century 
61 (Dakin, 1912). Annual landings in England and Wales equated to $4500 \mathrm{t}$ in 1911 (Dakin, 1912) and

62 European waters remain the principal area of fishing effort (FAO, 2017). The fishery has undergone

63 significant economic and geographical expansion in response to emerging Asian markets, with global

64 landings increasing from 7,000 $\mathrm{t} \mathrm{yr}^{-1}$ to over 35,000 $\mathrm{t} \mathrm{yr}^{-1}$ between 1990 and 2014 (FAO, 2017). The

65 effects of fishing mortality $(F)$ on the phenotypic traits of $B$. undatum may be significant, especially

66 considering the expansion in commercial exploitation (Kuparinen \& Merilä, 2007). Whelk are now

67 amongst the most economically important shellfisheries in the UK (Haig et al., 2015) with total UK

68 landings (21,606 t) equating to a value of $£ 21.7$ million in 2016 (MMO, 2017). Regionally, the Irish Sea

69 (ICES Area VIIa) has seen an estimated 227\% increase in the total landed weight of whelk between 2011

70 and 2016 and is the source of approximately $10 \%$ of global landings for this species. The most substantial

71 increases in recorded landings in the region are from within the Isle of Man territorial sea (ICES rectangle 37E5) and Welsh waters (ICES rectangles 33E5, 34E5, 35E5) (IFISH2, 2017; Figure 1).

73

$<$ Figure 1>

Figure 1. The spatial distribution of whelk (Buccinum undatum) landings in ICES Area VIIa by British vessels in 2011 (A) and 2016 (B) by ICES Rectangle. Source: IFISH2 database.

Within ICES Area VIIa, management regimes are not consistent. Similar to many other jurisdictions in the UK, whelk fisheries within Welsh waters are managed solely by a minimum landing size (MLS = 45 mm Total shell length; TSL) established by the European Union (EU), which has been shown to be inadequate in several studies (Shelmerdine et al., 2015; Haig et al., 2015). However, Isle of Man fisheries are subject to a MLS of $70 \mathrm{~mm}$ TSL, informed by Kideys et al. (1993) and the fishery now includes a restricted number of species-specific licenses, each of which has effort (pot number) restrictions.

The phenotypic plasticity displayed by other marine gastropod populations can be closely related to mortality and growth rates (Stearns \& Koella, 1986), which vary spatially and temporally with fishing pressure (Torrogolsa \& Gimenez, 2010; Fahy et al., 1995). Whelks do not reach sexual maturity for several years, have limited dispersal potential (Martel et al., 1986a) and display little adult movement (Pálsson et al., 2014; Weetman et al., 2006). Therefore, populations are inherently vulnerable to high $F$ and are particularly susceptible to recruitment overfishing (Shrives et al., 2015) and severe localised depletion (Nicholson \& Evans, 1997). Environmental parameters have been shown to influence the 
biological characteristics of populations, with size-at-maturity being negatively correlated to bottomtemperature but positively correlated with depth (McIntyre et al., 2015; Haig et al., 2015). This is unsurprising given that the common whelk is a boreal species, although no clear latitudinal relationship has been observed (McIntyre et al., 2015) and local factors such as food availability and fishing presure are likely to have an influence in maturation and growth (Martel et al., 1986b).

There is presently little scientific evidence to suggest that the current MLS of $45 \mathrm{~mm}$ used as the baseline throughout the EU is an adequate fisheries threshold for sustainable exploitation. Shelmerdine et al. (2007) suggests that management measures should be considered on a regional basis after demonstrating significant differences in the biology of whelk populations sampled in Shetland and the south-coast of England. Haig et al., (2015) shows that the size at maturity ( $\left.\mathrm{L}_{50}\right)$ can vary considerably between populations over distances as small as $10 \mathrm{~km}$ (although application of management measures at this spatial scale are acknowledged to be impractical). Complications arrise when trying to compare research on size-at-maturity, as there is not currently a standard scientific methodology to determine this metric (Haig et al., 2015).

This study combines published data (Haig et al., 2015) from Welsh waters with data collected in the Isle of Man territorial sea. The aim was to compare spatial variation in size-at-maturity and also to determine reproductive response to spatial, temporal and environmental parameters.

\subsection{Materials and methods}

\subsection{Field Materials (Fisheries Dependent Data)}

Nine fishers, registered in Wales (3), England (1) and the Isle of Man (5), each fished two identical whelk pots once a month within the ICES area VIIa (Irish Sea). The fishers retained the entire pot contents, including undersized bycatch and non-target species. The pots supplied to fishers were 36 litre Fish-tec ${ }^{\mathrm{TM}}$ 'WHELKER' pots, described by fishers as being 'stand-up' pots due to their orientation (Haig et al., 2015). The pots are made of thick plastic and are weighted with lead. The drainage holes in the base of the pot measure $30 \mathrm{~mm}$ in diameter and the entrance to the pot is covered with a purse-pull mesh netting. 
121 Fishers completed data-forms with details on the location (latitude and longitude), date, soak-time and

122 bait used. Isle of Man (Manx) samples were collected for a period of 12 months beginning in January

123 2016, with samples also collected in a pilot study in the Isle of Man during 2015. The Manx samples

124 were compared to Welsh data collected over a 14-month period beginning in April 2013 (Haig et al.,

125 2015). The general locations of the samples are displayed by area code to maintain commercial

126 confidentiality (see Figure 2). The pots were fished separately and attached to commercial fishing

127 'strings', which varied in length but typically anchor between 20 and 50 pots to the seabed along ropes

128 400-700 $\mathrm{m}$ in length. The pots were baited with a combination of dogfish (Scyliorhinus canicula) and

129 edible crab carcass (Cancer pagurus) and were 'soaked' for 24-48 hours.

130

131

132

133

134

135

136

137

138

139

140

141 A randomly selected subsamples of 30 individuals were taken from each pot-sample and further analysed.

142 The penis length (PL) was measured from the point of attachment to the body to the tip accounting for

143 natural curvature. Maximum and minimum shell width was recorded as shown in Haig et al. (2015).

144 Additionally, the subsamples were dissected and the animal was removed from the shell. The wet weight

145 of the flesh was recorded $(0.01 \mathrm{~g})$. The posterior lobe of the digestive gland, which is partially covered

146 by the gonad on the dorsal surface, was visually inspected and the degree of differentiation (\% GONAD; 0 ,

$1470.25,0.5,0.75,1)$ between the two organs was used to assign one of five maturity stages shown in table

148 (Haig et al., 2015; Hollyman, 2017a)

149

150
$<$ Table 1> 
152 The digestive gland and gonad, which are encapsulated by the same membrane forming the integument,

153 were dissected away at the area where the anterior edge of the digestive gland meets the renal gland and

154 weighed. The gonadosomatic index (GSI) was calculated by expressing the weight of the removed whorl mass (gonad and digestive gland) as a percentage of the wet flesh weight:

156

GSI $(\%)=\frac{\text { Gonad }+ \text { Digestive Gland }}{\text { Total wet flesh weight }}$

158

Additionally, an adjusted gonadosomatic index (aGSI) was calculated by multiplying the above GSI

160 value by the estimated proportion of the whorl occupied by the gonad gland (\% gonad) in an attempt to

161 focus analysis on reproductive patterns (as in Hollyman, 2017), where:

162

$a G S I=G S I \times \%_{G O N A D}$

\subsection{Statistical Analysis}

All analysis was carried out in the statistical software programme R v 3.3.1 (R Core Team, 2014). Prior to statistical modelling, shell measurement and weight data were tested for normality (KolmogorovSmirnov test) and inspected visually using a Q-Q plot. Heteroscedasticity was tested using the Levene's test and Cook's distance plot was used to check for outliers. Transformations were applied to data where

171 appropriate to achieve a normal distribution.

173 Significant deviation from the expected 1:1 ratio of sex ratio was tested using Chi-square test. Visual

174 assessment of the gonadal maturity stage $(G)$ (table 1) was used to determine a binary factor of functional maturity (immature or mature; see Table 1). Similarly, a binary factor indicating maturity in male data was also calculated using a penis-length index $\left(\mathrm{PL}_{i}\right)$, whereby if the ratio of penis length:total shell length is $\geq 0.5$, the individual was considered behaviourally mature (PL50) ( $($ Koie, 1969; Fahy et al., 2005).

179 Size-at-maturity estimates, the size at which $50 \%$ of the population is mature according to either $G$ or

$180 P L_{i}$, were made using the logistic regression model (Roa et al., 1999) reformulated by (Walker, 2005) to 181 give: 
$183 \quad P_{i}=\left\{1+e^{-\ln (19) \frac{T S L_{i}-T S L_{50}}{T S L_{95}-T S L_{50}}}\right\}^{-1}$

184

185 where $P_{i}$ is the proportion of the population that is mature at a given size, TSL 50 and TSL95 refer to the

186 lengths at which $50 \%$ and $95 \%$ of the population are mature respectively. Model parameters were

187 estimated using generalized linear model with logit link function and a binomial error structure.

188 Confidence intervals were assessed by bootstrapping the model (1000 runs). The base R code for plotting

189 the maturity ogives was constructed by Harry (2013) and has been adopted by Haig et al. (2015) and

190 Hollyman (2017). The maturity estimates for both TSL 50 and PL 50 are considered for temporal and spatial

191 variation.

192

193 To investigate whether TSL was the only factor that had a significant effect on $\mathrm{L}_{50}$ estimates, data were

194 analysed using generalised additive models (GAMs) in R. Modelling was conducted with the package

195 'mgcv' (Wood, 2017). Models were fitted using a binomial error distribution and a logit link function.

196 Modelling attempted to employ a backward selection, reducing the complexity (number of parametric

197 terms) by comparing AIC values (a model with an AIC value two points lower than a comparable model

198 was preferred).

199

200 The $\mathrm{PL}_{50}$ estimates for a male population, by way of further validation, is considered against an iterative

201 search procedure on the relationship between TSL and PL, whereby PL is modelled against TSL using

202 piecewise regression. The model examines the linear morphological relationship (PL:TSL) and searches

203 for significant deviation from the linear model, indicating maturation (an increase in $P L_{i}$ ). The method

204 searches each potential inflection (c) within a predetermined range until it has found the point at which

205 the total residual mean standard error is minimised (Crawley, 2007). The model is described by the

206 following equation:

207

$208 \quad y_{i}=\left\{\frac{\beta_{0}+\beta_{1} C W_{i}<c}{\beta_{2}+\beta_{3} C W_{i} \geq c}\right\}$ 
210 where $y_{i}$ is the TSL of individual $i, c$ is a breakpoint (inflection) between linear relationships applying

211 above and below the value of TSL equal to $c$, and the parameter $\beta$ parameters are the intercepts and slopes

212 of the two linear relationships.

214 Temporal spatial variation in aGSI were displayed visually using the 'ggplot2' package in R and 215 investigated using univariate techniques analyses of variance and covariance. Post-hoc analysis consisted 216 of Tukey HSD tests with visual display of temporal-spatial trends using boxplots. Similarly, frequency 217 histograms are used to display size-frequency data, which were used to make inferences on general 218 population structure. Variation in population structure (TSL distribution) over time and space was 219 investigated using the non-parametric Mann-Whitney $U$ test or, if exploration revealed data to be 220 normally distributed, $t$-test was employed for comparisons.

Depth data was assigned to each pot-sample using a high-resolution bathymetry layer $\left(1 \mathrm{~m}^{2}\right)$ downloaded from EMODnet (EMODnet Bathymetry Consortium, 2017). Since the possibility that whelk feed on small infaunal animals cannot be excluded (Himmelman \& Hamel, 1993), TSL and aGSI data were plotted against estimates of benthic infaunal biomass $\left(\mathrm{g} \mathrm{m}^{-2}\right.$ of wet mass; $\left.\mathrm{g} \mathrm{WM} \mathrm{m}^{-2}\right)$, modelled by (Whiteley, 2013, p. 103), to observe any effect of benthic ecology on population structures and reproductive biology.

Due to the time and resource constraints on the present study, age-analysis of the statoliths (as described in Hollyman, 2017 and Hollyman et al., 2017) were not possible; however, the biological material for

231 this analysis has been retained and will be investigated in the future. Therefore, when frequency 232 histograms showed multi-modal distributions, length-frequency analysis within the mixed distribution 233 was investigated as a proxy for size-at-age analysis. Using the R packages 'MIXTOOLS v1.0.3' (Young 234 et al., 2017) and 'MIXDIST v0.5' (Macdonald \& Du, 2012), the estimated mean and standard deviation 235 of the cohorts were calculated and exported to MS Excel. Within Excel, the data was modelled using the 236 LINEST function to estimate the coefficient values of the quadratic relationship along with the $\mathrm{R}^{2}$ value. 
240 A total of 9,234 whelks were collected by fishers for the present study in ICES area VIIa with an average

241 sex ratio of 1.14:1 females to male, which was significantly different from the expected 1:1 ratio $\left(\chi^{2}=\right.$ 242 24.077, $\mathrm{p}<0.001$ ). The sex ratio varied temporally (Fig. 3).

Figure 3. The average sex-ratio (F:M) of whelk (Buccinum undatum) samples collected throughout the study period \pm standard deviation. The red dotted line represents the expected ratio of 1:1.

248 The sample size varied both temporally and spatially due to the fisheries dependent nature of the study

249 (see table 2), thereby restricting the number of statistical comparisons available. A total of 3,290 individuals were selected as subsamples and underwent dissection. Gonadal assessment (\%GONAD) was successfully recorded for 2,451 .

Linear regression on $\log$ transformed data revealed a significant relationship between total weight and total shell length $\left(\mathrm{R}^{2}=0.952, \mathrm{p}<0.001\right)$ described using the equation $W=a L^{b}$, where $\mathrm{a}=2.6 \times 10^{-4}$ and $\mathrm{b}=2.795$. Further analysis showed that this relationship did not have a significant interaction with sex but there was a significant interaction with country (ANOVA; $F_{1,169.2}=25.382 ; \mathrm{p}<0.001$ ) (Figure 4a) with the average whelk sampled in Welsh waters attaining more weight per mm TSL.

The size distribution of whelk sampled within the Isle of Man territorial sea was significantly larger than that of Welsh waters (Mann-Whitney U Test; $p<0.001$ ), with the mean average being $77.7 \pm 15.9 \mathrm{~mm}$ TSL and 72.0 $\pm 18.1 \mathrm{~mm}$ respectively. TSL data for male and female whelk were not significantly different in Wales, but were in the Isle of Man (Mann-Whitney U Test; $p<0.001$ ). Significant spatial variation was observed in the length distribution (TSL) of whelks throughout sampled areas in ICES Area VIIa (ANOVA; $F_{9,8687}=266.3, p<0.001$; Figure $4 d$ ). Post-hoc Tukey HSD testing revealed significant differences $(\mathrm{p}<0.05)$ in the TSL distribution did not occur between all areas, as indicated by the lettering in figure $4 \mathrm{~d}$. 
Figure 4. a) The total shell length (TSL; mm) by total wet weight (g) relationship for whelk, Buccinum undatum, in the Irish Sea (ICES Area VIIa). $4 \mathrm{~b} \& 4 \mathrm{c}$ ) Length frequency histograms of the total shell length distribution for whelks from Wales (4a) and Isle of Man (4b) in temporally pooled data, with percentages above indicating the relative density of each $10 \mathrm{~mm}$ bin. The vertical $(4 \mathrm{~b}, 4 \mathrm{c})$ and horizontal (4d) red lines represent the current minimum landing size in each fishery jurisdiction. Figure $4 \mathrm{~d}$ shows the temporally aggregated TSL data for each survey area, displayed as boxplots. The letters above $4 \mathrm{~d}$ indicate a significant difference $(\mathrm{p}<0.05)$, whereby matching letters indicate no significant difference. The white and grey boxplots represent Welsh and Isle of Man samples respectively.

Generalized linear models with a binomial distribution were applied to the aggregated dataset, which in the Irish Sea (Fig. 5).

Figure 5. Maturity ogives showing the functional maturity estimates of whelk (Buccinum undatum) populations sampled in ICES Area VIIa during the study period. Three separate models were applied to female, male and combined sex data. The hashed lines represent the $95 \%$ confidence intervals of the model.

The narrow 95\% intervals suggest a high level of confidence in the models applied to aggregated data,

which showed TSL to be a highly significant explanatory variable for maturity $(\mathrm{p}<0.001$ in all three models). The smallest observed mature animal was observed at a size of $43 \mathrm{~mm}$ in Fishguard (West

Environmental or seasonal variables that might influence the proportion of mature whelk were considered further within general additive models, which were reduced in complexity according to a backward selection. The simplest model was able to explain $44.3 \%$ of the deviance (adjusted- $\mathrm{R}^{2}=0.497$ ) in the data $($ AIC value $=1894)$, described as;

305 The modeled parametric coefficients are summarised in table 4. Note that "s" denotes an isotropic smoother applied to depth data ( $($ Depth $)$, edf $\left.=1.193, \chi^{2}=1.362, \mathrm{p}=0.491\right)$. 
310 The results from the GAM showed that the most significant terms to influence the binary response

311 variable 'mature', were size, month, area and sex. In agreement with previous studies, size-at-maturity 312 estimates are therefore modelled using the GLM approach separately for males and females on a finer 313 temporal-spatial scale.

315 Considering that the month in which the sample is acquired has a significant effect on the response 316 variable 'mature', a rationale is required for determining the time-period during which data should be 317 modelled to estimate $\mathrm{L}_{50}$. The objective is to minimise false classifications of an individual animals 318 maturity stage (Table 1). Gonadal state is most visibly clear during a time period when ovaries and testes 319 of mature animals are full, after having fully recovered from previous spawning. This period can be determined by analysis of the variation in gonadosomatic index.

Analysis of covariance found that the pattern in adjusted-GSI (aGSI) varied significantly amongst mature whelks, explained by sex $\left(F_{1,7081}=452.8, p<0.001\right)$, month $\left(F_{11,3525}=20.5, p<0.001\right)$ and area $\left(F_{9,2646}=18.8, p=0.001\right)$, with significant interactions also between month and area $\left(F_{37,1946}=3.36, p<\right.$ $0.001)$, month and $\operatorname{sex}\left(F_{11,1148}=6.67, p<0.001\right)$ as well as area and $\operatorname{sex}\left(F_{9,400}=1.02, p=0.002\right)$. The aGSI pattern for male and female populations samples, aggregated by month and country (Isle of Man and Wales) are visually displayed in figure 6.

Figure 6. Boxplots showing the median average, IQ-range and 95\% CIs of aGSI: A) mature male and 331 female populations of whelk (Buccinum undatum) sampled in Welsh waters and B) the Isle of Man

335 Mature female whelk sampled within the Isle of Man territorial sea show a distinct reproductive cycle, 336 with peak aGSI during July to September (Fig 6b). Welsh data within ICES VIIa reveales that whelk had 337 a greater temporal range of peak aGSI, spanning from June until November (Fig 6a) with much greater variation. 
340 Estimated aGSI varied significantly according to season (Fig 6c) (ANOVA; $F_{3,2996}=23.91, p<0.001$ ),

341 with significant differences occurring between all seasons aside from between winter (December -

342 February) and spring (March - May) (Tukey post hoc, $\left.p_{\text {adj }}<0.001\right)$ and peaking during summer (June -

343 August). Similarly, aGSI varied significantly between maturity stages (6d) (ANOVA; $F_{4,40587}=487.7, p$

$344<0.001$ ), with significant differences occurring between all maturity stages (Tukey post hoc, $p_{\text {adj }}<0.001$ )

345 with the exception of between ' 5 ; recovering' and ' 3 ; ripe' (Tukey post hoc, $p_{\text {adj }}=0.99$ ) and ' 5 ;

346 recovering' and '4; spent' (Tukey post hoc, $p_{\text {adj }}=0.32$ ), with 'ripe' whelk having the greatest average

347 aGSI value.

349 Considering the analysis above, the most appropriate subset with which to conduct spatial comparisons 350 of functional maturity $\mathrm{L}_{50}$ is during summer and autumn (Fig 6a, 6b) prior to the spawning season, which 351 is characterised by a low aGSI value. Again employing a GLM approach, $\mathrm{L}_{50}$ is calculated for male and 352 female whelk within each area, with data aggregated throughout the peak aGSI period. The results of the 353 analysis, together with the sample size are presented in table 5.

$<$ Table 5>

357 Penis length was also assessed in order to estimate size at maturity using temporally aggregated data.

358 Logistic regression analysis estimated that the size at behavioural maturity for males $\left(\mathrm{PL}_{50}\right)$ for whelk in 359 Welsh waters is at a size TSL $=78 \mathrm{~mm}$; however, iterative searches observed an 'inflection' in the 360 PL:TSL relationship at a size TSL $=68 \mathrm{~mm}$. Similarly, for data aggregated from samples within the Isle 361 of Man, $\mathrm{PL}_{50}$ is estimated at a size $81 \mathrm{~mm}$, whereas an inflection in the PL:TSL relationship is observed 362 in the same data at a size TSL $=77$. In both sets of data, an allometric change in the penis is observed 363 before PL50 is observed.

365 Neither the reproductive output (aGSI; Fig7a), nor size (TSL distribution; Fig 7b), showed a clear trend 366 with modelled benthic infaunal biomass. Nonetheless, statistical testing revealed a significant difference 367 in the size distribution (TSL; ANOVA, $F_{6,6838}=53.17, p<0.001$ ) and reproductive output (aGSI; 368 ANOVA, $\left.F_{6,1552}=575.2, p<0.001\right)$ of whelk in areas of varying benthic infaunal biomass. Post-hoc 

between group, there is no clear correlative pattern. Note that dissected whelk from areas with a benthic infaunal biomass > $300 \mathrm{~g} \mathrm{WM} \mathrm{m}^{-2}$ did show an aGSI value approximately $100 \%$ greater than elsewhere; however, a low sample size $(n=19)$ limits the confidence in the statistical result (Fig 7a; $\left.D^{*}\right)$. In contrast, depth (analysed here as a categorical variable), appears to have a negative relationship with both reproductive output (aGSI) and average size (TSL). Average ovary weight (ANOVA; $F_{5,1743}=16.15, p$ $<0.001)$ and average size (ANOVA; $\left.F_{5,8346}=64.86, p<0.001\right)$ varies significantly between depth categories. Post-hoc Tukey HSD tests show that significant differences are generally observed between groups with increasing depth (Figure 7c and 7d).

Figure 7. Reproductive output (aGSI \%) and population structure (TSL; mm) displayed as boxplots plotted across two grouped environmental parameters; Benthic infaunal biomass $\left(\mathrm{g} \mathrm{WM} \mathrm{m}^{-2}\right)$ and depth (m). The letters indicate where post-hoc testing revealed significant differences in data, whereby matching letters indicate no statistically significant differences between data.

A sample, from within the NORTH survey area in March $2016(n=427)$, showed a multi-modal distribution (Hartigan's dip test for uni-modality; $\mathrm{D}_{12.37}=0.014, p$-value $=0.83$ [alternative hypothesis accepted, i.e at least bimodal]) with between five and seven modal intervals (cohorts). Using a mixedpopulation cohort analysis, summary statistics (mean and standard deviation) estimates for individual cohorts may be indicative of the population size-at-age relationship (Fig. 8). The estimates suggest that whelk in this area initially grow approximately $15 \mathrm{~mm} \mathrm{yr}^{-1}$ with the rate of growth decreasing with age. In the fifth year of growth, whelk reach the MLS (70 mm TSL). Since the sample was collected in March, it is also assumed that individuals have undergone a full annual growth period since initial spawning (age $0)$.

Figure 8. a) A probability density histogram showing the multi-modal TSL distribution of whelk within a single pot sample (NORTH-March 2016). The green lines show the probability function of the mixed data and the red lines show the modelled distribution of each estimated modal interval. The red arrows on the $\mathrm{x}$-axis represent the mean value of the modal intervals; b) a scatter plot showing the estimated size-at-age relationship modelled using the results of the multi-modal analysis. The points represent the average value of each modal interval (red arrows in fig $8 \mathrm{a}) \pm$ standard deviation. The quadratic term and $\mathrm{R}^{2}$ value are shown.

\subsection{Discussion}


405 The whelk fishery in the Irish Sea (ICES Area VIIa) has recently undergone significant expansion both

406 in terms of landings and effort (MMO, 2017), with landings increasing from 2,900 $\mathrm{t} \mathrm{yr}^{-1}$ to over 6,700 t

$407 \mathrm{yr}^{-1}(+227 \%)$ between 2011 and 2016, with a similar trend observed globally (FAO, 2017). Our results

408 suggest that, with the exception of one site to the north of the Isle of Man, there is a risk of recruitment

409 overfishing as the average whelk recruits into the fishery (at $45 \mathrm{~mm}$ in Wales and $70 \mathrm{~mm}$ TSL in the Isle

410 of Man) before they have an opportunity to spawn. It is possible that fishing under the size at maturity

411 may already have resulted in recruitment overfishing in principal fishing grounds in the Irish Sea. This

412 may culminate in long-term stock depletion in a fishery that is increasingly valuable to coastal and island

413 economies in the Irish Sea (DEFA, 2017).

415 Routine stock assessments are absent throughout the vast majority of the whelk fishery distribution, with 416 the exception of the States of Jersey, which began annual data collection in 1996 using baited-pots (Morel 417 \& Bossy, 2004; Shrives et al., 2015) and the inshore waters of Québec, where commercial fishery 418 performance indicators (catch per unit effort; CPUE) are assessed every three years (Brulotte, 2015). 419 There are methodological challenges in using capture data from baited-pots to estimate absolute or 420 relative population densities (Borsetti et al., 2018), considering the unknown effects of highly variable 421 environmental parameters such as tidal strength, season, bait-type and soak-time as well as the inherent sex-specific or size-specific selectivity of whelk pots (McQuinn et al., 1988). An improved sampling method may be to use dredge-based surveys. In a similar study, Borsetti et al. (2018) used a dredgebased survey methodology, whilst acknowleding that gear-specific efficiency studies for dredges may

425 facilitate absolute abundance assessments in the future. However, in the absence of accepted methods to conduct annual stock assessments, the sustainable prosecution of the whelk resources in the Irish Sea is 427 difficult to manage. Fisheries managers in the region now seek to manage whelk fishing with robust evidence (DEFA, 2017; Welsh Government, 2017) and transition towards routine assessments of stock 429 health. The results presented in this paper detail important population parameters, such as size-at430 maturity, size-at-age and length weight relationships $\left(W=a L^{b}\right)$, which are essential components of 431 biomass estimates in several stock-assessment techniques. Moreover, the variation within national waters 432 (see table 3 and table 5) may also need to be considered if future stock assessments are attempted at a 433 finer spatial scale, which has been the advice from other studies (Shelmerdine et al., 2007). 
435 The sex-ratio was significantly different to the expected 1:1 ratio, indicating that the catch efficiency of

436 static-gear is higher for females. This is particularly evident during late winter and spring, when females

437 are recovering from egg-laying and are likely to be attracted to baited pots to feed after spawning in order

438 to replenish energy reserves. Similar patterns were observed in data collected elsewhere in the region

439 (Hollyman P. R., 2017a, p. 40). The consistent removal of a higher proportion of females may result in

440 sex overfishing under a sustained level of heavy fishing pressure, which has been shown for other species

441 targeted by static-gear fisheries in the region (Emmerson et al., 2017). In order to protect spawning stock

442 biomass, the sex-dependent selectivity of gear, as well as the underlying biological and environmental

443 drivers, should be carefully considered in a management strategy that may include temporal fishery

444 closures (Hollyman, 2017, p. 294). The results from models presented here highlight that size-at-maturity

$445\left(\mathrm{~L}_{50}\right)$ and the reproductive cycle of whelks are vital elements of evidence for fisheries managers that wish

446 to initiate appropriate management measures to protect spawning biomass, such as MLS and temporal

447 closures to protect spawning.

449 The length frequency distribution shows significant spatial variation between country and between intra-

450 national fishing grounds. This is also important to policy-makers that need to consider the spatially

451 variable economic impact of a legislative change in MLS. Apart from a correlation between average

452 whelk size and water depth, other important environmental and ecological drivers remain poorly

453 understood for the species such as habitat type, sea bottom temperature and salinity. Benthic infauna

454 biomass, the foundation of the benthic food-web, was hypothesised to influence the mean size of whelk,

455 though no correlative relationship with TSL distribution was observed in the data. It remains possible

456 that benthic infauna biomass correlates with whelk population density, though further investigation is

457 needed to test this hypothesis. The indication that smaller whelk, with lower aGSI values (i.e. lower

458 relative weight of ovaries to total body weight), were caught in deeper waters suggests that there could

459 be habitat partitioning of life history stages driven by biological (food availability and reproductive

460 needs) and environmental (sea-bottom temperature and substrate type) preferences.

462 Increased temporal monitoring of population structure should reveal how whelks respond to both 463 environmental and anthropogenic factors, such as climate change as well as direct and indirect fishing 464 mortality. The population structure of whelk in the inshore grounds to the east of Douglas exhibit a 
similar size range (TSL) to that reported by Kideys (1991), suggesting that the levels of fishing experienced in recent years may not have impacted length frequency. This is notwithstanding the increase in fishing effort in other sectors of the industry, which may have either positive or negative, direct or indirect impacts on whelk populations. Within the Isle of Man territorial sea, the principal whelk grounds are subject to heavy fishing pressure from scallop trawling (Shepperson et al., 2014). Bottom-towed, or trawling gear, is known to impact other commercially fished species; for example, egg-bearing female

471 brown crabs are regularly caught as bycatch in the Isle of Man scallop gear (Ondes et al., 2016).

472 Conversely, trawling indirectly influences common whelk populations by providing additional food 473 resources in the form of damaged bivalves, echinoderms, and crustaceans following trawling disturbance 474 (Ramsey et al., 1998). The scavenging opportunities created by benthic disturbance may be a significant 475 energetic input for whelk populations considering the results presented in this study, that benthic infauna biomass shows no clear correlation to whelk population parameters. Understanding this interaction would be a positive step towards ecosystem-based management, a process which would require mapping of commercial effort in order to quantify the cumulative impacts of indirect and direct interactions between fisheries (Murray et al., 2008).

The analysis presented in this paper exhibits progress towards understanding the reproductive cycle of whelk populations in the Irish Sea and, importantly, provides clear rationale for routine assessment of maturity in this region and elsewhere. The methodology discussed, that maturity analysis should be conducted during peak-aGSI, is in agreement with other recent work (Hollyman, 2017, p. 287). McIntyre et al. (2015) attempted to minimize seasonal variability in their analysis of SOM in various English locations by collecting samples during January - May. However, under the assumption that whelk populations in the English Channel and North Sea also spawn in late winter, McIntyre et al. (2015) likely overestimated $\mathrm{L}_{50}$ due to low aGSI values in the sampled whelk. Martel et al., (1986b) calculated GSI values with eviscerated weight (total meat weight minus the weight of the testis, digestive gland and seminal vesicle for males, and the total weight minus the weight of the ovary, digestive glans and pallial 491 oviduct for females) used as the denominator, in contrast to this study which used total meat weight. Arguably, eviscerated weight would provide a more accurate GSI as the weight of reproductive organs

493 vary temporally. However, as Welsh data did not include eviscerated weight and in order to conduct a regional comparison in the Irish Sea, the same methodology was adopted for Manx samples. This 
demonstrates the need for the adoption of a standard assessment protocol to enable comparisons between

different studies, in different regions and in different countries. This will become increasingly important to understand the broader scale impacts of increasing fishing pressure as well as climate change and ocean warming. Sea surface temperature data strongly suggests that seasonal onset of maturity, as indicated by an increase in aGSI values within a population (indicating the development and ripening of gonadal organs) being linked to local temperature regimes. Historical sea-surface temperature (SST) data

501 for the Irish Sea region highlights a potential correlative relationship, considering that SST peaks in the Isle of Man during July, August and September (exceeding $13^{\circ} \mathrm{C}$ ), whereas peak SST from Welsh waters shows a more prolonged temporal period within which temperature data exceeding $13^{\circ} \mathrm{C}$, observed from June until November (CEFAS, 2017). However, a greater temporal data-set of aGSI is necessary to understand whether temperature may have a causative effect on aGSI observations. Benthic temperatures would provide a more comprehensive picture, particularly if the water column is highly stratified. The temporal patterns observed show that ovaries are most full during July to September in the Isle of Man, which was also observed by Kideys (1991), and from June to November in Welsh samples.

Growth was assessed using mixed-modality analysis of length-based data. Identifying growth parameters

511 using direct observations made in laboratory or by investigating statolith ring analysis was outside the scope of this study, although samples have been retained for analysis using the methods developed by

513 Hollyman et al. (2017). Nonetheless, the size-at-age model presented here provides some preliminary 514 detail on growth, which is an important consideration when interpreting $\mathrm{L}_{50}$ values, as well as potentially 515 modelling recovery rates of depleted populations and formulating advice for temporal datasets in sizeat-maturity. It is recommended that size-at-maturity estimates are repeated over a period of time relevant 517 to the life-history of a species (EU, 2010). In this case, the advice is to perform biennial assessments of 518 size-at-maturity and model the change in the mean average $\mathrm{L}_{50}$ of the current and previous assessment

519 (i.e a moving four-year average, a time-period which approximates to age of the average whelk beginning 520 to develop reproductive organs) (ICES, 2008). This method helps alleviate sampling variability, 521 maturity-stage uncertainty and significant changes in fishing practices; however, it may also mask genuine changes in population parameters caused by environmental or anthropogenic factors (ICES, 

regimes due to climate change.

When fitting a logistic curve to the maturity data, it does not always follow that output value $\left(\mathrm{L}_{50}\right)$ should be the recommended MLS. It is important to account for additional information when available, such seasonality and frequency of spawning events (including skipped spawning events as in gadoid species)

530 as well as fecundity-at-size estimates and eggs-per-recruit models (ICES, 2008). In the case of whelk in

531 the Irish Sea, the appropriate time for maturity assessment (i.e. peak-aGSI, when reproductive organs 532 exhibit the clearest distinction between mature and immature) is between June and September. However, our results suggest that egg-laying occurs in late winter, during which time the assessed population is expected to have grown beyond the $\mathrm{L}_{50}$ estimate. During that period in the Irish Sea, our data indicates population sampled "North" of the Isle of Man in this study produced an $\mathrm{L}_{50}$ estimate of $67 \mathrm{~mm}$ TSL.

\subsection{Conclusion}

This study provides the most comprehensive scientific evidence to date with which to manage and conserve the common whelk resources within ICES Area VIIa. Additionally, we propose a clear rationale for undertaking routine assessments biennially for size-at-maturity, which are biologically-referenced to the time at which aGSI is at a peak in the population and visual classification of gonads is most accurate. The evidence presented here suggests whelk are subject to fishing mortality before they have the opportunity to lay eggs for the first time with the existing MLS regulations. Although no data is available to indicate that populations are recruitment overfished, current understanding of whelk biology suggests that a precautionary approach should be adopted in order to conserve resources in the light of this 
554 This project would not have been possible without the help of the Welsh Fisherman's Association

555 (WFA), the Manx Fish Producers Organisation (MFPO) and other members of the fishing industry that 556 voluntarily provided biological samples. The project was funded in Wales by the European Fisheries 557 Fund (EFF) and in the Isle of Man by the Isle of Man Government's Department for Environment, Food $558 \&$ Agriculture (DEFA). We would also like to extend our gratitude to all those who contributed to the 559 laboratory analysis of samples, including Jennifer Langdon, Edward Bolger, Tom Busbridge, Jennifer 560 Fox, Gemma Godwin, Metthew King, Dawn Watson, Harriet Lincoln, Claire Lambden and Julia Pantin.

561 We would also like to thank Karen McHarg, director of Fisheries at DEFA, for her comments on a draft 562 version of this paper. Finally, we would like to thank the anonymous reviewers for their comments, which greatly improved this paper.

\section{References}

Ager, O. E. (2008). Buccinum undatum Common Whelk. In H. Tyler-Walters, \& K. Hiscock, Marine Life Information Network: Biology and Sensitivity Key Information Reviews [online]. Plymouth: Marine Biological Association of the United Kingdom.

Borsetti, S., Munroe, D., Rudders, D. B., Dobson, C., \& Bochenek, E. A. (2018). Spatial variation in life history characteristics of waved whelk (Buccinum undatum L.) on the U.S. Mid-Atlantic continental shelf. Fisheries Research, 198, 129-137.

Brulotte, S. (2015). Whelk Stock Assessment in Québec's Inshore Waters - Methodology and Results. DFO Can. Sci. Advis. Sec. Res. Doc. 2015/045. xii + 80p.

CEFAS. (2017). Sea temperature and salinity trends. Lowestoft, UK: CEFAS Data Hub. Retrieved 11 21, 2017, from https://www.cefas.co.uk/cefas-data-hub/sea-temperature-and-salinitytrends/station-positions-and-data-index/

Crawley, M. J. (2007). The R Book. West Sussex, UK: Wiley, Blackwell.

Dakin, W. (1912). Memoirs on Typical British Marine Plants and Animals: Buccinum (the Whelk). Liverpool Mrine Biology Commitee Memoirs, 20, 123.

DEFA. (2017). Proposals for Future Management of the Isle of Man Whelk Fishery. Public Consultation, Isle of Man Government, Department for Environment, Food and Agriculture, St John's. Retrieved from https://consult.gov.im/environment-food-and-agriculture/whelkfishery/

DEFA. (2017). Weight and Value of Fish Landed by Species 2005-2016. Digest to the Cabinet Office. Isle of Man Government, Department for Environment, Food and Agriculture, St John's. Retrieved from unpublished data

Emmerson, J. A., Haig, J. A., Robson, G., Hinz, H., Le Vay, L., \& Kaiser, M. J. (2017). Size-selective fishing of Palaemon serratus (Decapoda, Palaemonidae) in Wales, UK: implications of sexual dimorphism and reproductive biology for fisheries management and conservation. Journal of the Marine Biological Association of the United Kingdom, 97(6), 1223-1232.

EMODnet Bathymetry Consortium. (2017). EMODnet Digital Bathymetry (DTM). Retrieved 0815 , 2017, from http://portal.emodnet-bathymetry.eu/help/help.html

European Union. (2010). Adopting a multiannual community programme for the collection, management and use of data in fisheries for the period 2011-2013. Official Journal of the European Union, Regulation L41/8(37). 
Fahy, E., Yalloway, G., \& Gleeson, P. (1995). Appraisal of the whelk Buccinum undatum fishery of the Southern Irish Sea with proposals for a management strategy,. Department of the Marine, Fisheries Research Centre. Dublin: Irish Fisheries Investigation Series B (Marine). Retrieved 13 11, 2017, from http://oar.marine.ie/

FAO. (2017). Species Fact Sheets: Buccinum undatum. Retrieved 01 27, 2017, from http://www.fao.org/fishery/species/2659/en

Haig, J. A., Pantin, J. R., Solomonsen, H., Murray, L. G., \& Kaiser, M. J. (2015). Temporal and spatial variation in size at maturity of the common whelk (Buccinum undatum). ICES Journal of Marine Science, 72(9), 2707-2719.

Harry, A. V. (2013). Maturity ogive in R. Retrieved 2 16, 2015, from https://gist.github.com/alharry/ 4576675

Himmelman, J. H. (1988). Movement of whelks (Buccinum undatum) towards a baited trap. Marine Biology, 97, 521-531.

Himmelman, J., \& Hamel, J. (1993). Diet, behaviour and reproduction of the whelk Buccinum undatum in the northern Gulf of St Lawrence, eastern Canada. Marine Biology, 116(3), 423-430.

Hollyman, P. R. (2017a). Age, growth and reproductive assessment of the whelk, Buccinum undatum, in coastal shelf seas. Bangor University, School of Ocean Sciences. Menai Bridge: $\mathrm{PhD}$ Thesis.

Hollyman, P., Leng, M. J., Chenery, S. R., Laptikhovsky, V. V., \& Richardson, C. A. (2017). Statoliths of the whelk Buccinum undatum: a novel age determination tool. Marine Ecology Progress Series. doi:https://doi.org/10.3354/meps12119

ICES. (2008). Report of the Workshop on Maturity Ogive Estimation for Stock Assessment (WKMOG). ICES Advisory Committee. Lisbon, Portugal: International Council for the Exploration of the Seas.

Kideys, A. E., Nash, R. D., \& Hartnoll, R. G. (1993). Reproductive cycle and energetic cost of reproduction of the neogastropod Buccinum undatum in the Irish Sea. Journal of the Marine Biological Association of the United Kingdom, 73, 391-403.

Koie, M. (1969). On the endoparasites of Buccinum undatum L. with spatial reference to trematodes. Ophelia, 6, 251-279.

Kuparinen, A., \& Merilä, J. (2007). Detecting and managing fisheries-induced evolution. Trends in Ecology \& Evolution, 22(12), 652-659.

Macdonald, P., \& Du, J. (2012, 10 29). Mixdist: Finite Mixture Distribution Models in R. Retrieved 08 10, 2017, from https://cran.r-project.org/web/packages/mixdist/index.html

Martel, A., Larrivee, D. H., \& Himmelman, J. H. (1986a). Behaviour and timing of copulation and egglaying in the neogastropod Buccinum undatum. Journal of Experimental Marine Biology and Ecology, 96, 27-42.

Martel, A., Larrivée, D. H., Kelin, K. R., \& Himmelman, J. H. (1986b). Reproductive cycle and seasonal fishing activity of the neogastropod Buccinum undatum. Marine Biology, 92(2), 211221.

McIntyre, R., Lawler, A., \& Masefield, R. (2015). Size of maturity of the common whelk, Buccinum undatum: Is the minimum landing size in England too low? Fisheries Research, 162, 53-57.

McQuinn, I. H., Gendron, L., \& Himmelman, J. H. (1988). Area of attraction and effective area fish by a whelk (Buccinum undatum) trap under variable conditions. Canadian Journal of Fisheries and Aquatic Science, 45, 2054-2060.

MMO. (2017). UK and foreign vessels landings by UK port and UK vessels landing abroad. Newcastle-upon-Tyne: Marine Management Organisation.

Morel, G. M., \& Bossy, S. F. (2004). Assessment of the whelk (Buccinum undatum L.) population around the Island of Jersey, Channel Isles. Fisheries Research, 68, 283-291. 
Murray, L. G., Hinz, H., \& Kaiser, M. J. (2008). Developing an ecosystem approach to the management of Manx fisheries. Report No. 5, Bangor University, Fisheries \& Conservation Science Group.

Nasution, S., \& Roberts, D. (2004). Laboratory trials on the effects of different diets on growth and survival of the common whelk, Buccinum undatum L. 1758, as a candidate species for aquaculture. Aquaculture International, 12, 509-521.

Nicholson, G. J., \& Evans, S. M. (1997). Anthropogenic impacts on the stocks of the common whelk Buccinum undatum (L.). Marine Environmental Research, 44, 305-314.

Ocean Biogeographic Information System. (2017). The global distribution Buccinum undatum. OBIOS. Retrieved 03 06, 2017, from http://iobis.org/mapper/?taxon=Buccinum\%20undatum

Ondes, F., Kaiser, M. J., \& Murray, L. G. (2016). Quantification of the indirect effects of scallop dredge fisheries on a brown crab fishery. Marine Environmental Research, 119, 136-143.

Pálsson, S., Magnúsdóttir, H., Reynisdóttir, S., Jónsson, Z. O., \& Ornólfsdóttir, E. B. (2014). Divergence and molecular variation in common whelk Buccinum undatum (Gastropoda: Bucinidae) in Iceland: A trans-Atlantic comparison. Biological Journal of the Linnean Society, 111, 145-159.

Ramsey, K., Kaiser, M. J., \& Hughes, R. N. (1998). Responses of benthic scavengers to fishing disturbance by towed gears in different habitats. Journal of Experimental Marine Biology and Ecology, 224, 73-89.

Roa, R., Ernst, B., \& Tapia, F. (1999). Estimation of size at sexual maturity: An evaluation of analytical and resampling procedures. Fishery Bulletin, 97, 570-580.

Shelmerdine, R. L., Adamson, J., Laurenson, C. H., \& Leslie, B. (2007). Size variation of the common whelk, Buccinum undatum, over large and small spatial scales: Potential implications for micro-management within the fishery. Fisheries Research, 86, 201-206.

Shepperson, J., Murrary, L. G., Cook, S., Whiteley, H., \& Kaiser, M. J. (2014). Methodological considerations when using local knowledge to infer spatial patterns of resource exploitation in an Irish Sea fishery. Biological Conservation, 180, 214-223.

Shrives, J. P., Pickup, S. E., \& Morel, G. M. (2015). Whelk (Buccinum undatum L.) stocks around the Island of Jersey, Channel Islands: Reassessment and implications for sustainable management. Fisheries Research, 167, 236-242.

Stearns, S. C., \& Koella, J. C. (1986). The evolution of phenotypic plasticity in life-history traits: Predictions of reaction norms for age and size at maturity. Evolution, 893-913, 40.

Torrogolsa, E. M., \& Gimenez, J. (2010). Temporal variation in size at maturity of the snail Zidona dufresnei from the southwestern Atlantic Ocean after ten years of fishery exploitation. Aquatic Biology, 11, 163-167.

Van Guelpen, L., Pohle, G., Vanden Berghe, E., \& Costello, M. J. (2005). Buccinum undatum. Retrieved from Marine Species Register for the Northwest North Atlantic Ocean: http://www.marinebiodiversity.ca/nonNARMS/

Walker, T. I. (2005). Reproduction in fisheries science. In W. C. Hamlett (Ed.), Reproductive Biology and Phylogeny of Chondrichthyans: Sharks, Batoids, and Chimaeras (pp. 81-127). Enfield, NH., USA: Science Publishers, Inc.

Weetman, D., Hauser, L., Bayes, M., Ellis, J., \& Shaw, P. (2006). Genetic population structure across a range of geographical scales in the commercially exploited marine gastropod Buccinum undatum. Marine Ecology Progress Series, 317, 157-169.

Welsh Government. (2017). Proposed sustainable management measures for the Welsh whelk fishery. Public Consultation, Welsh Government, Marine and Fisheries. Retrieved from https://consultations.gov.wales/consultations/proposed-sustainable-management-measureswelsh-whelk-fishery

Whiteley, H. (2013). The utility of benthic infuanal production for selecting marine protected areas in the Irish Sea. School of Ocean Sciences: Bangor Univserity. 
694 Wood, S. (2017, 9 19). Mixed GAM Computation Vehicle with Automatic Smoothness Estimation.

695 Retrieved 08 31, 2017, from https://cran.r-project.org/web/packages/mgcv/mgcv.pdf

696 Young, D., Benaglia, T., Chauveau, D., Hunter, D., Elmore, R., Hettmansperger, T., ... Xuan, F.

697 (2017, 03 10). Mixtools: Tools for analysizing finite mixture models in R. Retrieved 0810 ,

698

2017, from https://cran.r-project.org/web/packages/mixtools/index.html

699 
Table 1. The maturity-stage classifications of whelk (Buccinum undatum) as determined from visual inspection of the reproductive organs.

705

\begin{tabular}{|c|c|c|c|}
\hline & Stage & Description & Mature \\
\hline 1 & Immature & $\begin{array}{l}\text { Gonad non-differentiated from digestive whorl. Penis }<25 \mathrm{~mm} \text {. VD } \\
\text { not visible. }\end{array}$ & 0 \\
\hline 2 & Developing & $\begin{array}{l}\text { Gonad beginning to differentiate on anterior edge of whorl but is } \\
\text { thin. Penis likely }<25 \mathrm{~mm} \text {. VD may be visible. }\end{array}$ & 1 \\
\hline 3 & $\begin{array}{l}\text { Mature } \\
\text { (ripe) }\end{array}$ & $\begin{array}{l}\text { Ovary is fully differentiated from digestive whorl and full ( } 3 / 4 \text { of } \\
\text { whorl volume). Penis }>25 \mathrm{~mm} \text { and VD visible. }\end{array}$ & 1 \\
\hline 4 & $\begin{array}{l}\text { Mature } \\
\text { (spent) }\end{array}$ & $\begin{array}{l}\text { Ovary is fully differentiated from digestive whorl but flaccid } \\
\text { (occupying } 1 / 4 \text { of whorl volume). Penis fully developed and VD } \\
\text { visible. }\end{array}$ & 1 \\
\hline 5 & $\begin{array}{l}\text { Mature } \\
\text { (recovering) }\end{array}$ & $\begin{array}{l}\text { Ovary is fully differentiated from digestive whorl, typically } \\
\text { occupying }>1.2 \text { whorl volume. Penis fully developed and VD } \\
\text { visible. }\end{array}$ & 1 \\
\hline
\end{tabular}


709 Table 2. The total number of whelks (Buccinum undatum) sampled via fisheries-dependent methods (caught with scientific pots on commercial strings) in each month for all locations throughout the study period (2013-2016). Italicised numbers represent data from Haig et al. (2015). 
VERSION CONTROL: V9 2017-11-21

712

\begin{tabular}{|c|c|c|c|c|c|c|c|c|c|c|c|c|}
\hline \multirow[b]{2}{*}{ Area-code } & \multicolumn{2}{|c|}{ Winter } & \multicolumn{3}{|c|}{ Spring } & \multicolumn{3}{|c|}{ Summer } & \multicolumn{3}{|c|}{ Autumn } & \multirow{2}{*}{$\begin{array}{c}\text { Winter } \\
\text { D }\end{array}$} \\
\hline & $\mathbf{J}$ & $\mathbf{F}$ & $\mathbf{M}$ & $\mathbf{A}$ & $\mathbf{M}$ & $\mathbf{J}$ & $\mathbf{J}$ & $\mathbf{A}$ & $\mathbf{S}$ & $\mathbf{O}$ & $\mathbf{N}$ & \\
\hline \multicolumn{13}{|l|}{2013} \\
\hline ANGLESEY & - & - & - & - & 91 & - & 87 & - & 68 & 152 & 212 & - \\
\hline LLYN & - & - & - & 257 & 365 & 182 & 168 & - & 53 & 128 & 38 & - \\
\hline FISHGUARD & - & - & - & 66 & 140 & 158 & 183 & - & 75 & 64 & - & - \\
\hline \multicolumn{13}{|l|}{2014} \\
\hline ANGLESEY & - & 57 & - & - & 112 & - & - & - & - & - & - & - \\
\hline LLYN & - & - & - & 69 & 332 & - & - & - & - & - & - & - \\
\hline FISHGUARD & - & 88 & 27 & - & - & - & - & - & - & - & - & - \\
\hline RAMSEY & - & - & - & - & - & - & - & 15 & - & - & - & - \\
\hline \multicolumn{13}{|l|}{2015} \\
\hline SOUTH & - & - & - & 46 & 63 & 79 & - & 34 & - & - & - & - \\
\hline SOUTHEAST & - & - & 42 & - & - & - & - & - & 79 & - & - & - \\
\hline EAST & 22 & 50 & - & - & - & - & - & - & - & 45 & - & - \\
\hline \multicolumn{13}{|l|}{2016} \\
\hline SOUTHEAST & 60 & 142 & 233 & 319 & 93 & 26 & - & - & - & 113 & - & - \\
\hline EAST & - & 68 & - & - & 77 & 16 & - & 66 & 200 & 193 & - & - \\
\hline NORTHEAST & - & - & - & - & - & 161 & 84 & - & 156 & 87 & - & - \\
\hline RAMSEY & - & - & - & 175 & 57 & - & - & - & - & - & - & - \\
\hline NORTH & - & 164 & 427 & 332 & 571 & 315 & - & - & 494 & - & 354 & - \\
\hline WEST & - & 138 & 51 & 54 & 20 & 61 & - & - & - & - & - & - \\
\hline
\end{tabular}

713 
$716<$ Table 3>

717 Table 3. The estimated values of coefficients $a$ and $b$ for the Length Weight relationship $W=a L^{b}$ for 718 whelk (Buccinum undatum) by area. The length weight relationship is applied to the current MLS in the 719 Isle of Man (70 mm TSL) to illustrate the variation.

$720<$ Table 3>

721

\begin{tabular}{|c|c|c|c|c|}
\hline & Area & $\mathrm{a}$ & $\mathrm{b}$ & $\operatorname{MLS}_{\text {IOM }}(\mathrm{g})$ \\
\hline \multirow{3}{*}{$\begin{array}{l}\text { 先 } \\
\frac{1}{3} \\
3\end{array}$} & ANG & 8.616 & 2.900 & 40.7 \\
\hline & LLYN & 7.152 & 2.562 & 41.9 \\
\hline & FSHGRD & 8.365 & 2.831 & 39.0 \\
\hline \multirow{7}{*}{ 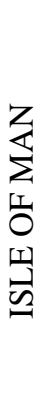 } & SOUTH & 8.775 & 2.909 & 35.9 \\
\hline & SOUTH-E & 8.510 & 2.835 & 34.3 \\
\hline & EAST & 8.120 & 2.750 & 35.3 \\
\hline & NORTH-E & 9.457 & 3.056 & 34.1 \\
\hline & RAM & 8.634 & 2.889 & 38.1 \\
\hline & NORTH & 9.001 & 2.956 & 35.2 \\
\hline & WEST & 8.762 & 2.919 & 38.2 \\
\hline
\end{tabular}

722 
$724<$ Table 4>

725 Table 4. The estimated parameters, $t$-values, Std. Error and $p$-values for the preferred general additive 726 model describing the relationship between maturity as a binary factor $(0,1$; immature, mature) and

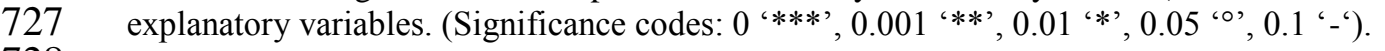

$728<$ Table 4>

729

\begin{tabular}{|c|c|c|c|c|}
\hline Parameters & Estimate & Std. Error & $t$-value & $p$-value \\
\hline (Intercept) & -11.65 & 0.68 & -17.21 & $<0.001$ \\
\hline TSL & 0.17 & 0.01 & 24.43 & $<0.001$ \\
\hline Area-EAST & -1.01 & 0.33 & -3.04 & 0.002 \\
\hline Area-FISHGUARD & -0.67 & 0.35 & -1.95 & 0.051 \\
\hline Area-LLYN & -1.20 & 0.37 & -3.23 & 0.001 \\
\hline Area-NORTH & -0.16 & 0.36 & -0.45 & 0.651 \\
\hline Area-NORTHEAST & -1.29 & 0.39 & -3.24 & 0.001 \\
\hline Area-RAMSEY & -0.79 & 0.52 & -1.52 & 0.129 \\
\hline Area-SOUTH & -1.03 & 0.42 & -2.44 & 0.015 \\
\hline Area-SOUTHEAST & -1.07 & 0.32 & -3.33 & $<0.001$ \\
\hline Area-WEST & -2.73 & 0.40 & -6.75 & $<0.001$ \\
\hline FEB & 1.06 & 0.35 & 2.99 & 0.003 \\
\hline MAR & 0.60 & 0.36 & 1.66 & 0.097 \\
\hline APR & 1.10 & 0.35 & 3.12 & 0.002 \\
\hline MAY & 1.67 & 0.36 & 4.57 & $<0.001$ \\
\hline JUN & 2.04 & 0.41 & 4.98 & $<0.001$ \\
\hline JUL & 1.14 & 0.42 & 2.70 & 0.007 \\
\hline AUG & 0.80 & 0.44 & 1.81 & 0.070 \\
\hline SEP & 0.92 & 0.37 & 2.51 & 0.012 \\
\hline OCT & 0.58 & 0.36 & 1.63 & 0.103 \\
\hline NOV & 0.38 & 0.43 & 0.87 & 0.385 \\
\hline DEC & 2.18 & 0.94 & 2.31 & 0.021 \\
\hline MALE & -0.34 & 0.12 & -2.87 & 0.004 \\
\hline
\end{tabular}


733 Table 5. Functional maturity $\left(\mathrm{L}_{50}\right)$ estimates for male and female whelk (Buccinum undatum) by study area within the Irish Sea (ICES Area VIIa) during the summer and autumn months (June to October). Caution should be taken when considering samples with low sample size; $* * *=\mathrm{N}$ too low to produce an estimate, $*=\mathrm{N}$ sufficient to produce an estimate, but with low confidence.

\begin{tabular}{|c|c|c|c|c|}
\hline & Area & Sex & $\mathrm{L}_{50}(\mathrm{~mm})$ & $N$ \\
\hline \multirow{6}{*}{$\begin{array}{l}\text { 至 } \\
\frac{1}{3} \\
3\end{array}$} & \multirow{2}{*}{ ANGLESEY } & $\hat{0}$ & 63.6 & 71 \\
\hline & & o & 65.6 & 78 \\
\hline & \multirow{2}{*}{ LLYN } & $\pi$ & 71.8 & 80 \\
\hline & & q & 71.3 & 86 \\
\hline & \multirow{2}{*}{ FISHGUARD } & $\sigma^{\pi}$ & 62.5 & 102 \\
\hline & & 우 & 65.5 & 89 \\
\hline \multirow{14}{*}{ 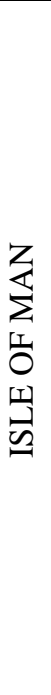 } & \multirow{2}{*}{ SOUTH } & $\pi$ & $71.1 *$ & 38 \\
\hline & & q & $63.9 *$ & 34 \\
\hline & \multirow{2}{*}{ SOUTH-E } & $\hat{\sigma}$ & 71.9 & 57 \\
\hline & & 우 & 73.1 & 68 \\
\hline & \multirow{2}{*}{ EAST } & $\hat{\sigma}$ & 74.9 & 100 \\
\hline & & q & 72.3 & 96 \\
\hline & \multirow{2}{*}{ NORTH-E } & $\hat{0}$ & 75.0 & 145 \\
\hline & & 우 & 71.6 & 132 \\
\hline & \multirow{2}{*}{ RAM } & $\hat{0}$ & NA*** & 5 \\
\hline & & q & NA*** & 5 \\
\hline & \multirow{2}{*}{ NORTH } & $\pi$ & 64.7 & 82 \\
\hline & & q & 67.3 & 79 \\
\hline & \multirow{2}{*}{ WEST } & $0^{\pi}$ & $65.5 *$ & 23 \\
\hline & & q & $75.1 *$ & 21 \\
\hline
\end{tabular}


VERSION CONTROL: $2^{\text {nd }}$ Submission. 2017-02-14

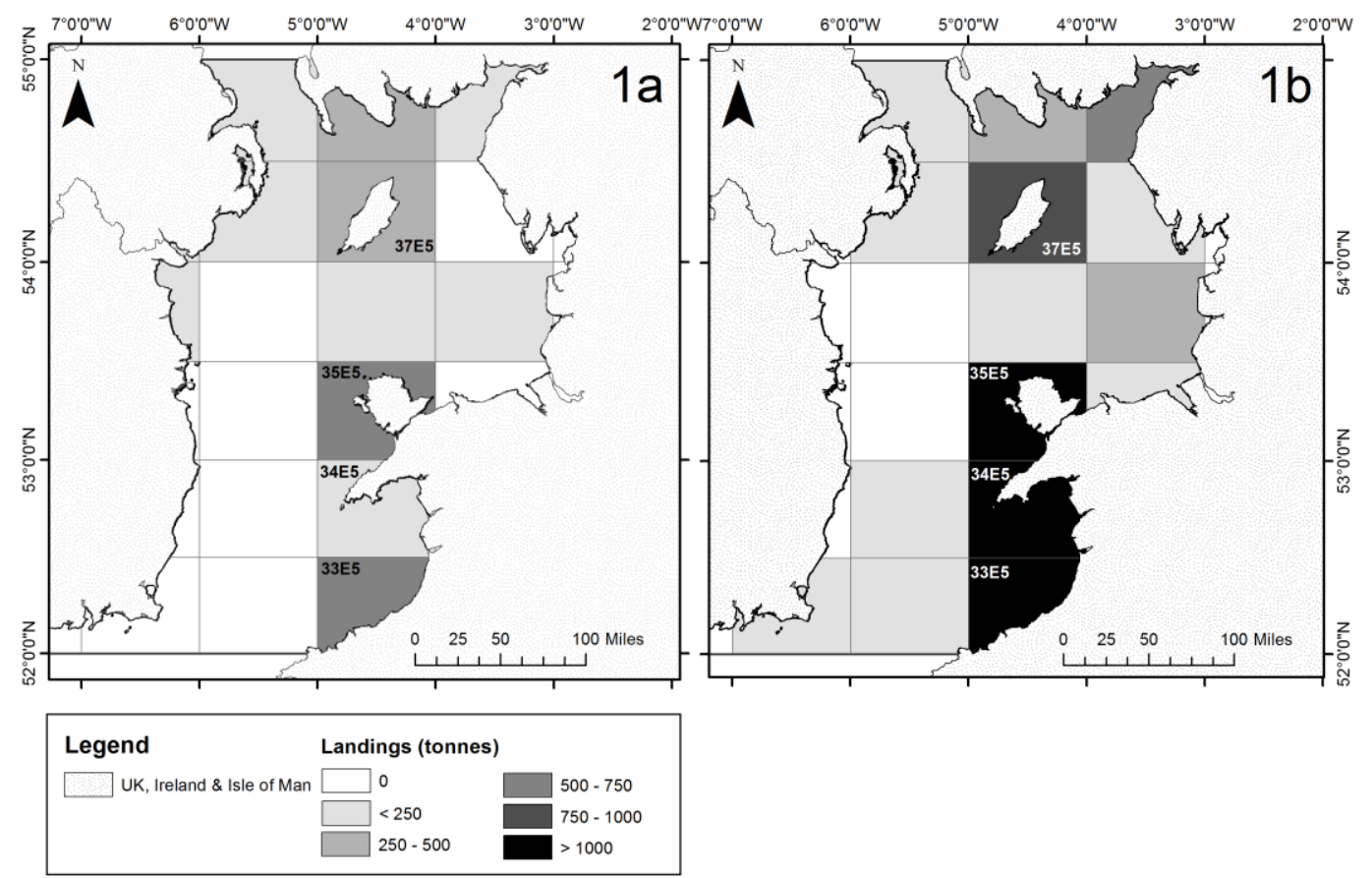

743

744 
VERSION CONTROL: $2^{\text {nd }}$ Submission. 2017-02-14

$745 \quad$ Fig 2

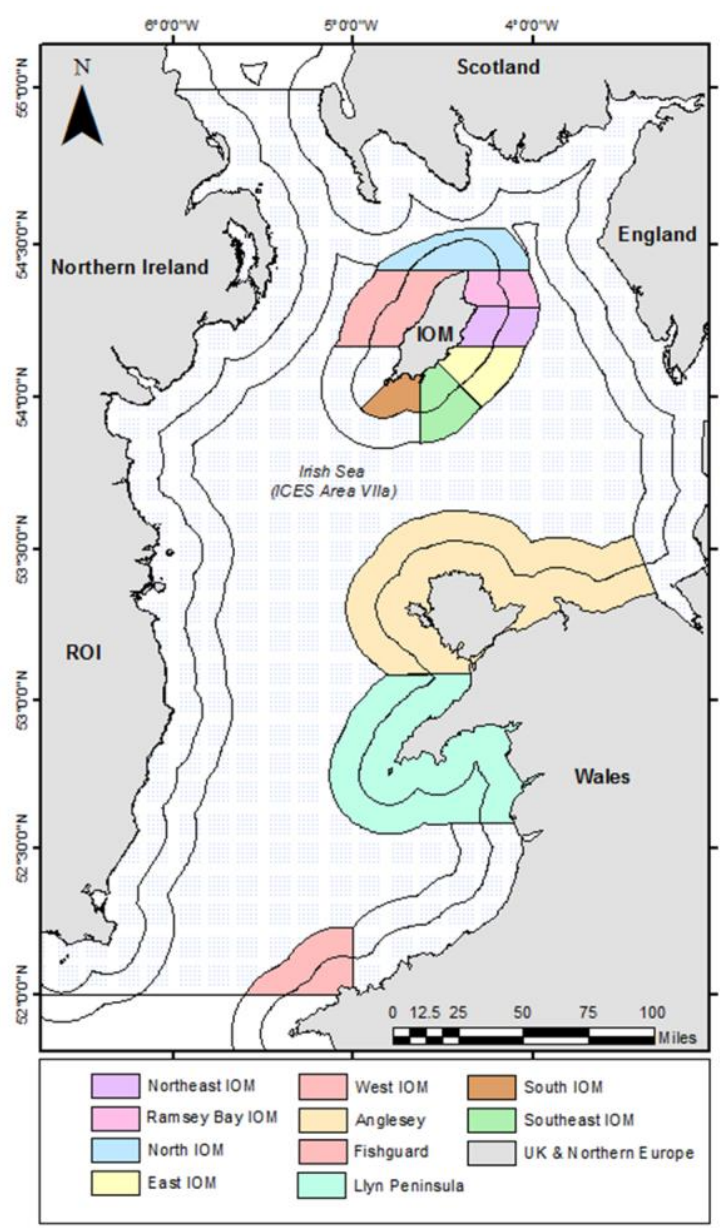

746 
$748 \quad$ Fig 3

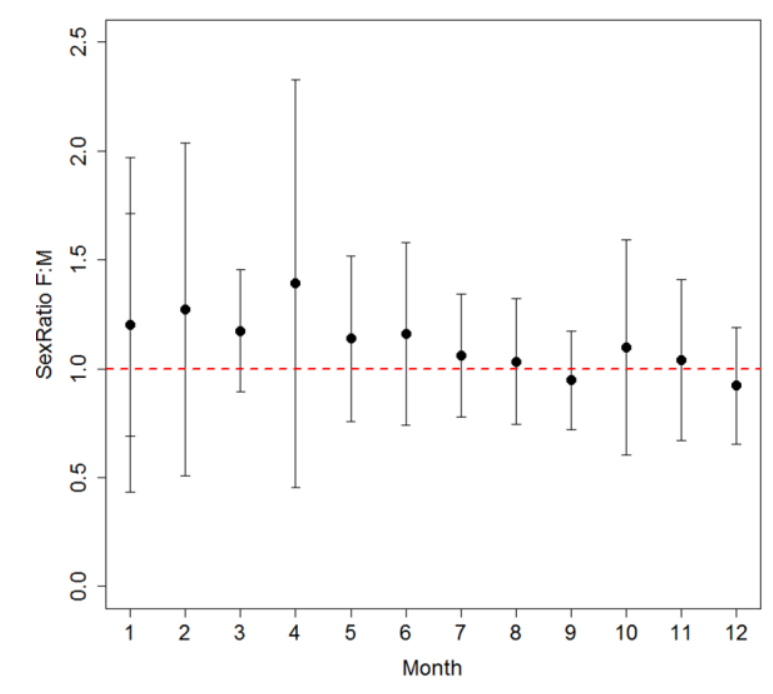

749

750 

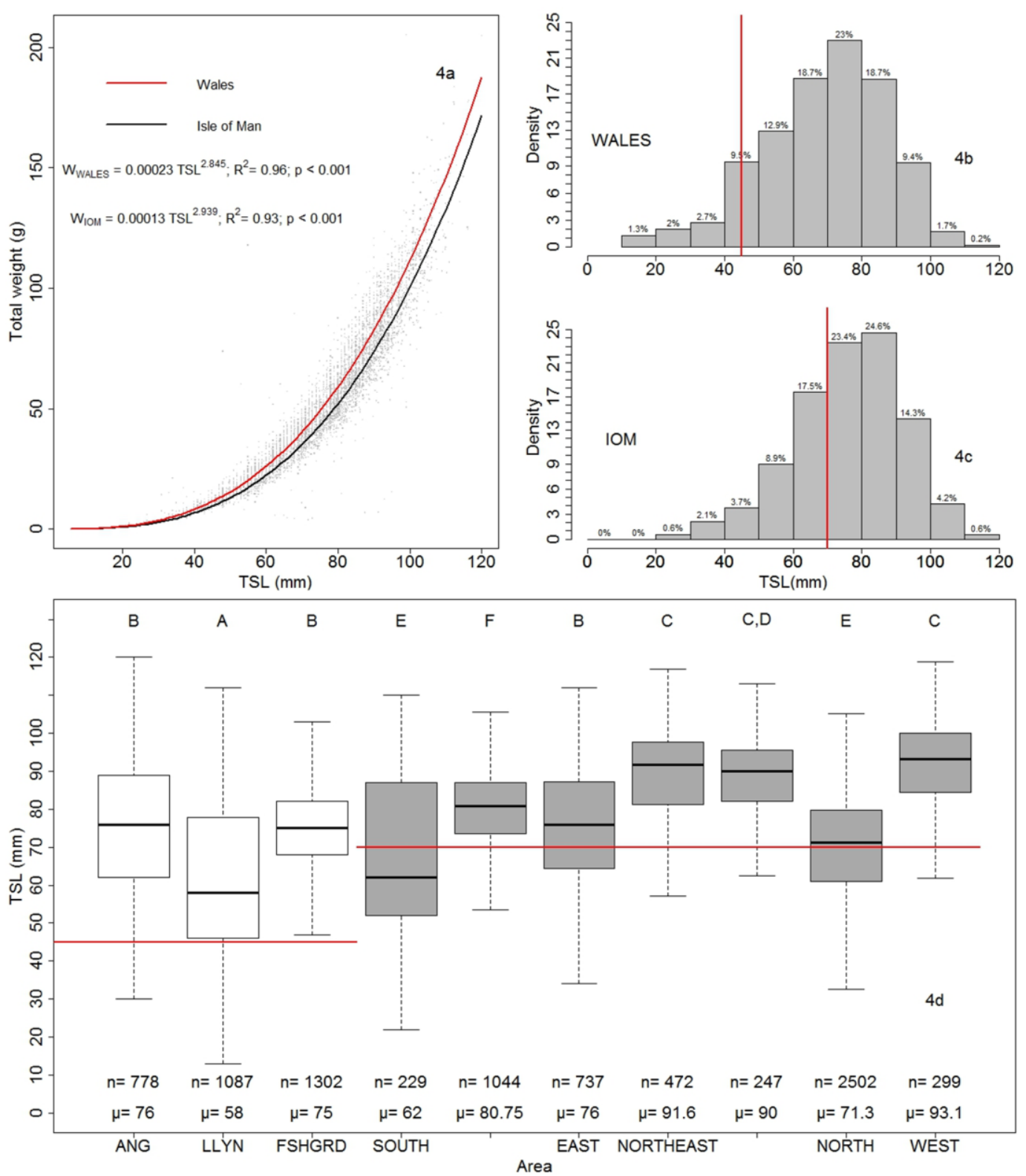

752 
$754 \quad$ Fig 5

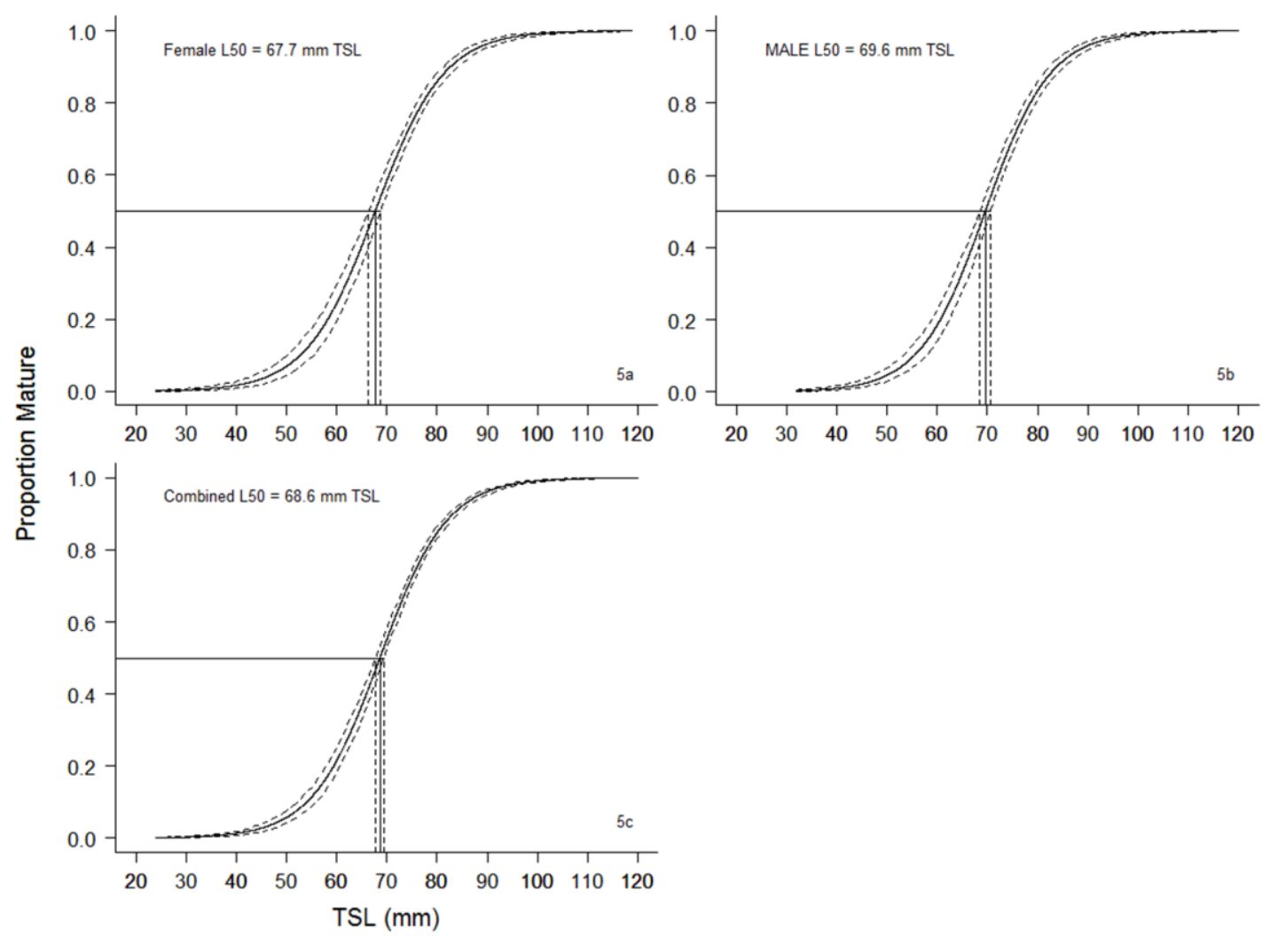

755

756 

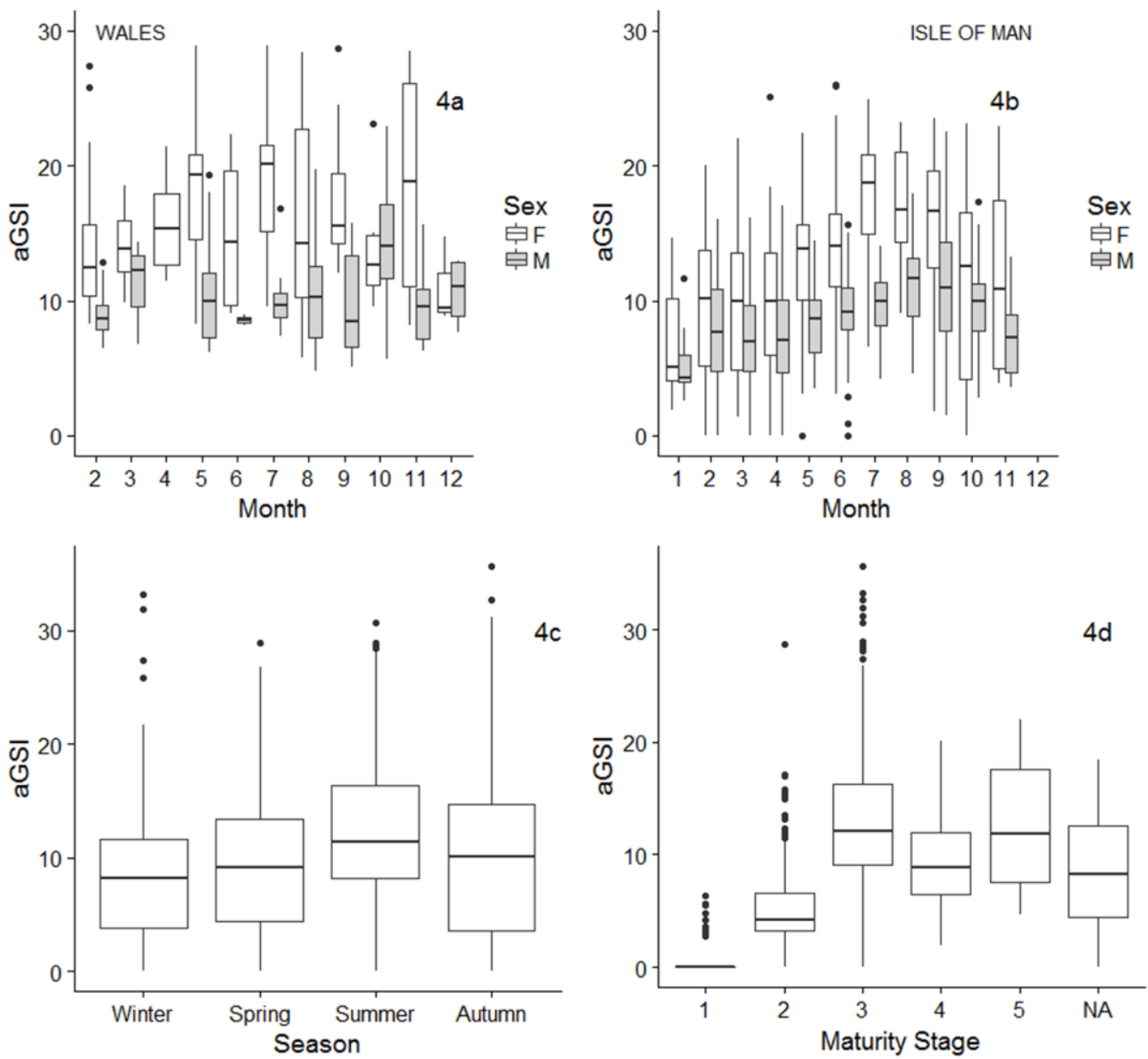
Fig 7
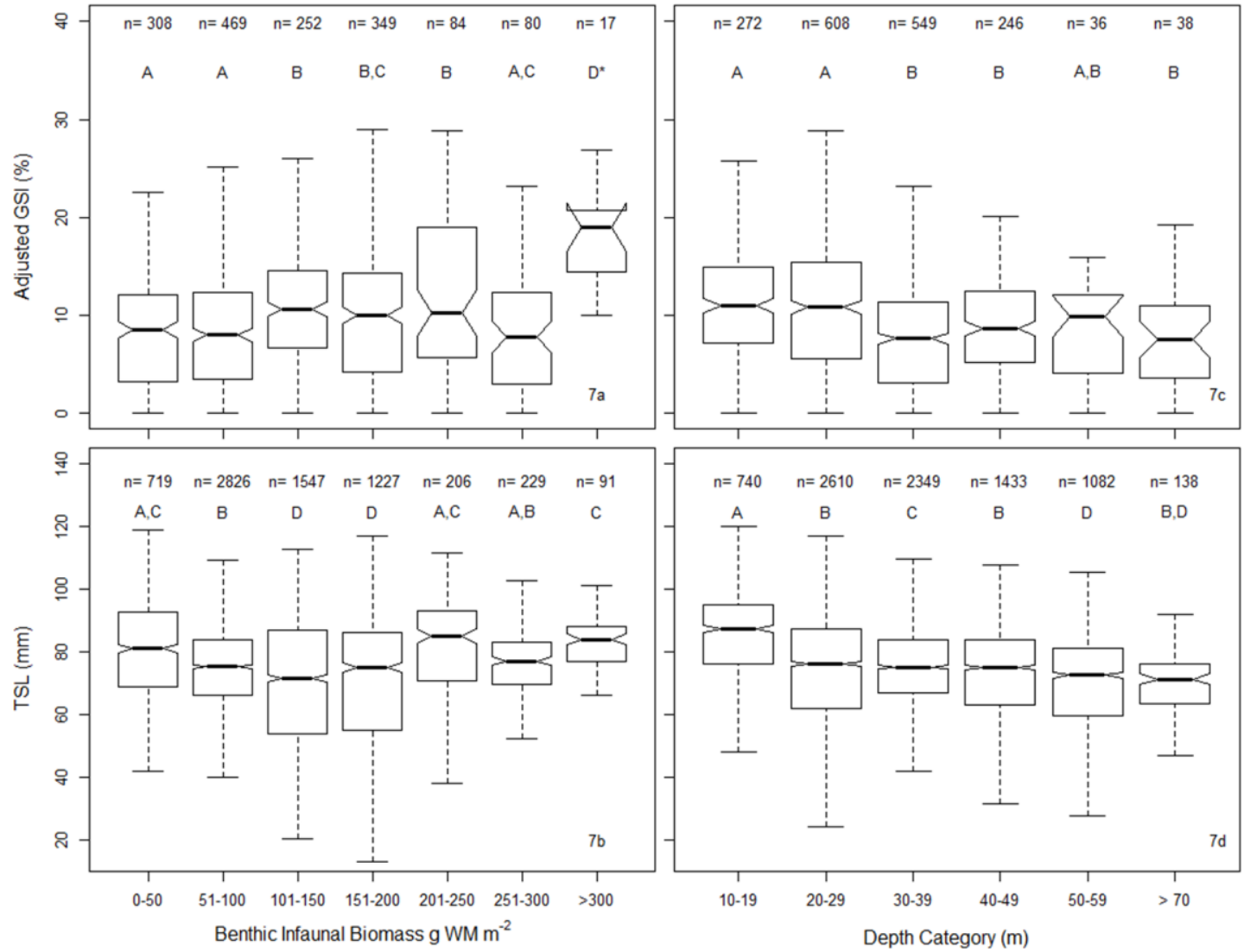

761

Benthic Infaunal Biomass $\mathrm{g} \mathrm{WM} \mathrm{m}^{-2}$ 
$763 \quad$ Fig 8
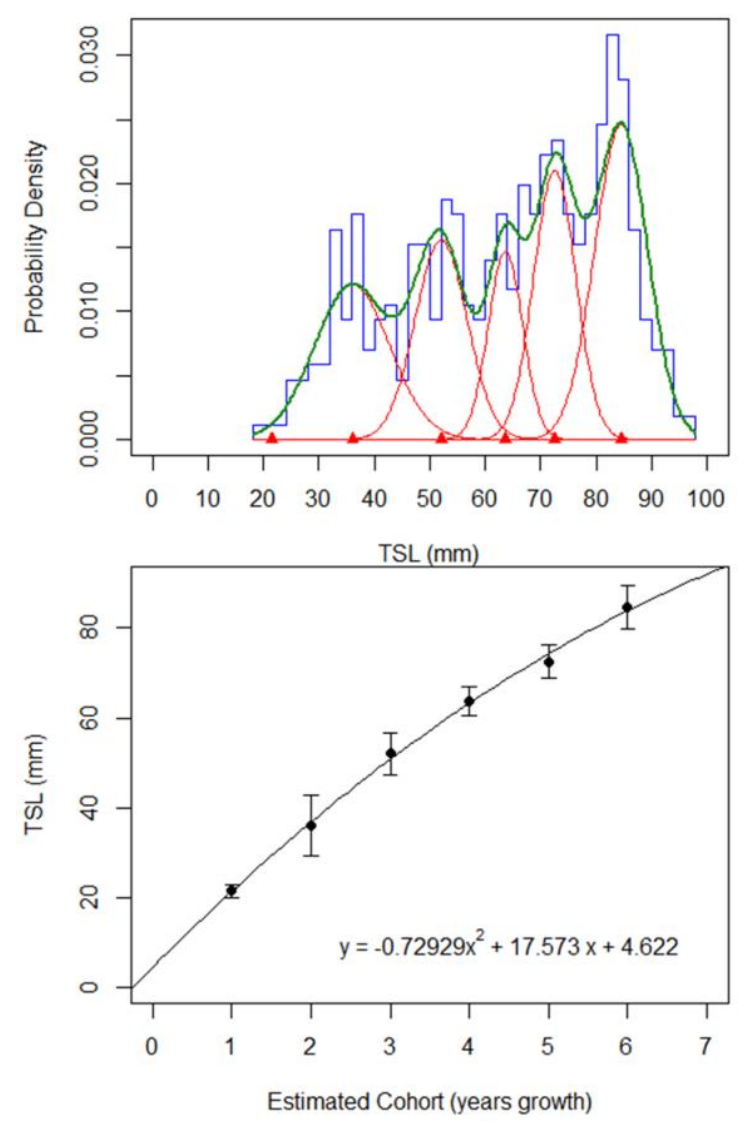

764 